\title{
Comprehensive Design and Manufacturing Solutions for Sand Control and Tooling towards Enhanced Oil Recovery
}

\author{
Yongsheng Ma
}

\begin{abstract}
This paper proposes an integrated and coherent research program includes phenomena discovery and investigation, product design, performance evaluation, failure mode analysis, interfacial and surface interaction enhancement, tooling product development and manufacturing technologies. The focused area is tooling system design and manufacturing of steam-assisted gravity drainage (SAGD) oil extraction technology. This study covers sand control liners and inflow and outflow control devices for in-situ heavy oil extraction. In order to provide solid scientific engineering input and analysis support, multi-disciplinary experts with a unique combination of strengths are suggested to form a team; hence the collective expertise covers a broad range of required scientific challenges. This proposed program leverages on knowledge-based and sustainable solutions with synergic, industry-oriented, and multidisciplinary collaboration approach.
\end{abstract}

Index Terms-Multi-disciplinary research, steam-assisted gravity drainage (SAGD), phenomenon modeling, semantic modeling.

\section{INTRODUCTION}

Canada's oil sands development [1] is a significant portion of Canada's national economy [2]. 20\% of the oil sands are suitable for open mining, which has high yields but creates environmentally challenging tailing ponds. Steam-assisted Gravity Drainage (SAGD) (see Fig. 1) and other "in-situ" enhanced recovery methods have been developed [3] to deal with deep oil sands deposits, but uncertainty in predicting productivity and evaluating investments has called into question the sustainability of the industry as a whole [4]. The production of heavy oil is deemed to be inefficient: recovery rates per well pair are approximately 55\% [3] and the amount of steam required to extract 1-barrel of oil is around 2.5-barrels [4]. Steam-Assisted Gravity Drainage (SAGD) is the major technological driver in this sector, but it has been an industry reality that in spite of the billions of dollars invested by oil companies for in-situ projects, the economic viability of such methods is still in question: While a few companies have developed workable SAGD methods, those technologies have been largely developed by trial and error or built from field experiences. Most research works to date have focused on SAGD reservoir-simulation, which is coarse in engineering scale and does not consider the tooling factor in application. To the best knowledge of the applicant, few

Manuscript received March 20, 2016 August 5, 2016. The author would like to thank RGL Reservoir Management Inc. for its financial support and background input regarding the current industrial practice. He would also like to acknowledge the useful input from the following collaborators of the University of Alberta: N. Alireza; C.F. Lange; J.L. Luo; D Nobes; and HB Zeng.

Yongsheng Ma is with the Dept. Mechanical Engineering, University of Alberta, Edmonton, Canada (e-mail: yongsheng.ma@ualberta.ca). researchers have looked into the interfacial phenomena and behaviors between underground tool strings and the oil sands formations. Organizations in this sector are seeking continuous improvements in production, efficiency, sustainability, and environmental impact. The lifespan of a typical SAGD well can be up to 25 years due to the large amount of oil that can be extracted from the area [2]. Bitumen extraction so far has been identified as a priority

'Enhanced oil recovery' describes technologies that use the injection of heat and chemicals into reservoirs to increase the production rate and the total amount of oil produced. The basic SAGD process (see Fig. 1) involves a pair of wells drilled horizontally and parallel through the reservoir. Steam is pumped into the reservoir through the injection well, generating a heat affected region where the viscosity of the bitumen is lowered. Under the effect of gravity, the hot bitumen drains down and is recovered through the production well. Sand control is vital to reliable production in heavy oil recovery processes because sand production is a major obstacle in heavy oil recovery [5], [6].

SAGD wells are typically completed with sand control devices in the horizontal section, such as slotted liner [5], [7]. Coberly [8] investigated bridging of the inside and outside of the slots based on a series of experimental tests. They concluded that D90 (i.e., sieve opening size that will allow the passage of $90 \%$ of sand grains) of the reservoir sand could be used for the slot size to allow the development of an effective arch behind the slots. Past experimental works for the slotted liner design have usually been performed considering only one single slot in the laboratory testing [9]. Flow performance is typically considered to be constrained by the open area exposed to the reservoir [10], but industrial feedback indicates that this is not the case for all reservoirs. Outflow Control Device (OCD) in injection wells and Inflow Control Devise (ICD) in production wells have been widely used in SAGD operations to customize steam distribution in the steam injector well and control the distribution of produced fluids. Kyanpour and Chen [11] used the wellbore-modeling tool CMG [12], FlexWellTM, and showed that the pattern of fluid flow control devices in both injector and producer wells can highly affect operational performance.

Horizontal wells are typically modeled by the sink/source numerical approach, which does not capture the accelerational and frictional pressure drop effects along the well. Oballa et al. [13] performed numerical analysis and demonstrated the effect of wellbore flow on reservoir behavior in terms of breakthrough time, and uneven communication between the wellbore and the reservoir. Several approaches have been introduced to incorporate wellbore flow in SAGD analysis [14]-[16]. They showed that discretized wellbore approach should be used for SAGD because: (1) the effect of the heat 
conduction between the wells and the reservoir is considerable; (2) large flow rates are expected; (3) frictional pressure drop in the injection/production wells is considerable; and, (4) reservoirs are not homogenous.

In the complex SAGD multi-phase system including steam, water, bitumen, sand and solid fine clays, the slotted liners face many detrimental issues such as electrochemical corrosion, plugging and fouling due to deposition of sand/clay and sedimentation of asphaltenes and so on [9], [17], [18]-[22]. All these would lead to failure of the liners and causes serious negative impact on production, which includes, but are not limited to, reduced bitumen production, poor sand control performances and lower quality of bitumen product (with considerable amounts of fine solids that further leads to difficulties in oil/solid/water separation and water treatment and recycling in SAGD operations). Coatings are widely used for corrosion protection [23], however, there are no reports on $\mathrm{H} 2 \mathrm{~S}$ resistant coating in open literature.

This work proposes an integrated research program that intends to identify effective and scientifically validated tools for use in the in-situ recovery of heavy oil by thermally and chemically enhanced means. The proposed research focuses on the development of simulations, product design engineering and manufacturing and application optimization, with critical support provided by research in complex interfacial physics and chemistry mechanisms, multiphase flow investigations and verification by experimental testing.

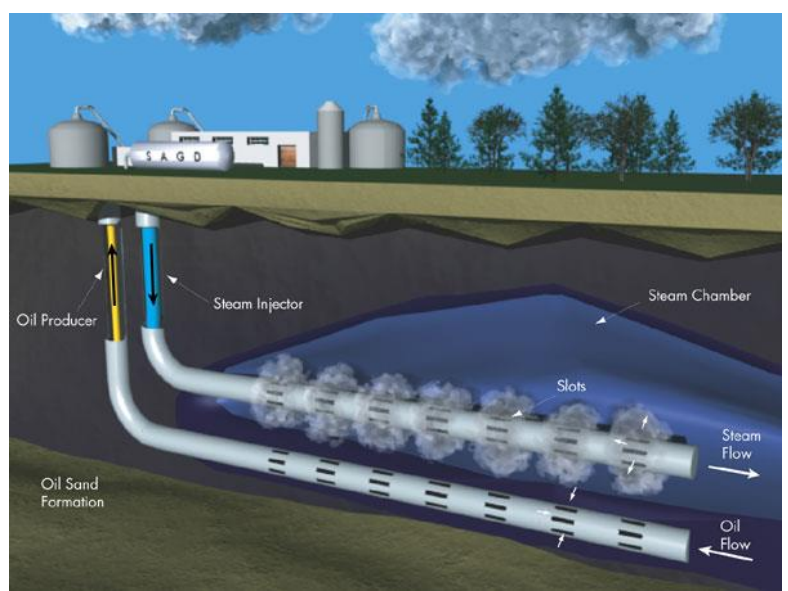

Fig. 1. SAGD production process (source: http://www.no-tar-sands.org/).

\section{THE RESEARCH APPROACH}

This research program requires a collaboration platform with regular strategic reviews to relate key disciplines through knowledge-based design and manufacturing principles, managed by the PI, where the findings of fundamentals research will be incorporated into design solutions that fulfil the technical objectives of the program. See Fig. 2 for a map of associations of phenomenon research with the work in design and manufacturing. An interconnected and iterative research process associates the following generic aspects:

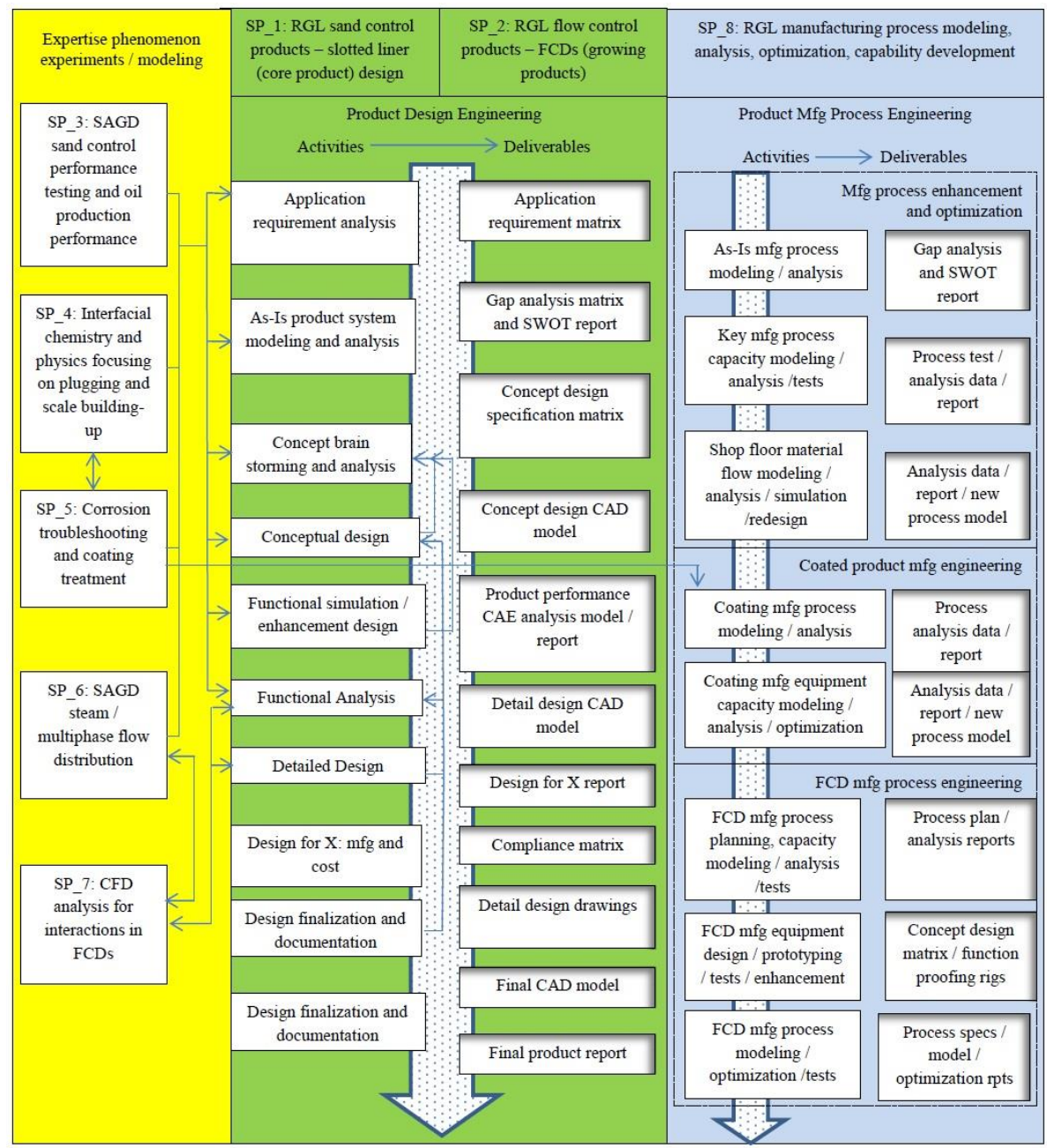

Fig. 2. Sub-Project associations with design and manufacturing research processes (arrows: information flows). 


\section{A. Data Collection}

The research team will collect relevant application data reported in the literature and within available industrial records. Such data will be categorized, classified and organized onto data maps to highlight application cases that represent qualified working conditions that the technology will be applied within. Wherever possible, standardized data characterizations from the literature, for example, the sand controlling findings by Kaiser et al. and Fermaniuk [24], [25], reservoir simulation established by Chen et al. [26], [27] and others [9], scaling building up and prevention efforts by [28]-[30], will be used. They will establish robust conditions for verification and validation. Different failure mechanisms are to be investigated as well.

\section{B. Phenomenon Investigation and Analysis}

The unique conditions found in a heavy oil reservoir precipitate the complex interaction of many different physical phenomena over many different scales. Specific testing investigations are required on fundamental aspects of these phenomena to allow the development of knowledge that can be used to predict failure mechanisms and optimize performance. A large amount of the effort in this research program will be dedicated to developing this fundamental knowledge. Such effort will underpin the development of predictive models and product designs.

\section{Phenomenon Simulation and Prediction}

Phenomenon mathematical models and their simulations is a core benefit that this research program will generate. These models will allow predictive calculations to be performed leading to design optimization. The models and simulations will consider predicting flow conditions and performance of different sand screen configurations and flow-control devices within the tooling system.

\section{Cyclic Design Analysis and Verification}

Engineering Design is a cyclic process and many product solutions are developed through long-term research and development processes. "Design for X" concept must be applied such that the design concepts can take care of different aspects of concern, i.e. X, with measured performance expectation, such as design for manufacturability, cost, reliability, corrosion protection, scaling prevention/cleaning, etc. Design models are in the form of CAD models, but the relevant data has to be extracted and used in semantic models to validate the design theoretically and numerically.

\section{E. Multi-stage Testing}

To prove a phenomenon model or evaluate a design solution, testing is essential to validate the theoretical models even though the testing environment can be costly. In this research program, three types of testing processes are considered: in-principle lab testing, mid-size simulated testing, and full-size production testing. Each testing process includes a set of engineered testing procedures. The mid-size simulated testing and full-size production testing will be done in collaboration with industrial companies. Different testing processes with different scales are designed to provide scalability and reliability evaluation, which is valuable input for the effectiveness of the theoretical models, computer models and the design solutions.

\section{F. Product Design Enhancement and System Optimization}

Embedding phenomenon models into the design models, design change management, and using simulation tools to validate designs will enable knowledge-based design engineering. A Product Data Management (PDM) tool will be used to manage design contents and change. Cyclic CAD and CAE interaction processes will be employed with parametric tracking techniques to ensure the design knowledge is explicitly represented, reused, and enhanced with different application optimization cases and configuration options.

\section{TECHNICAL ASPECTS}

In order to study the multidisciplinary research capabilities required, industrial needs were assessed and classified into functional aspects, and mapped to expertise disciplines. With the projected interdisciplinary dependencies, the proposed program requires collaboration with experts in several fields including industrial input as well as robust experimental validation. The related research components are also aligned under the following industrial requirements: (I) Heavy oil reservoir engineering, (II) Downhole tool design, and (III) Tooling manufacturing.

\section{A. Sand Screen Liner Mechanism Study, Semantic \\ Product Model, and Testing Facility (I)}

A laboratory facility is proposed for full-scale testing of SAGD completion performance. The research is expected to lead to improved liner design criteria and a comparative study of slotted liner performance against other types of sand control.

\section{B. Near-Wellbore Reservoir Simulation (I)}

The proposed simulation model, an integrated well-flow reservoir model linked to a geomechanical model, will facilitate the investigation of the inflow/outflow distribution and pressure profile in the stream injection and production wells, as well as the steam breakthrough and sub-cool analysis in response to operational conditions. Geo-mechanical effects will be included to capture changes in permeability and porosity due to potential near-hole annular collapse and shear dilation in the reservoir.

\section{Sand Screen Liner Design Optimization (II)}

With findings of cyclic failure modes and effects analysis as design inputs, the team will analyze opportunities for improvement and investigate changes in design to eventually deliver a new slotted liner product design with optimized performance as a design target.

\section{Flow Control Device Computational Fluid Dynamics (CFD) Model (II)}

A comprehensive numerical model will be developed, focused exclusively on the flow through liner slots, flow control devices, in order to provide quantitative assessment of the effect of design and manufacturing modifications. This focus will enable the model to achieve an unprecedented 
level of detail and accuracy. Fig. 3 shows a set of currently available flow control products.

\section{E. Tooling System Design Optimization (II)}

This component focuses on the internal mechanisms within flow control devices, as well as the hangers, packers, and other tools used in thermal completions. Long term reliability of these tools is of special interest.

\section{F. Manufacturing Technology Feasibility Study (III)}

Effective alternative manufacturing mechanisms should be explored for different modular and adjustable products. These potential solutions will be modeled from both technical and economic angles. The feasibility of implementation will be critically and realistically evaluated. For examples, manufacturing slot liners uses a range of custom-built multi-spindle horizontal milling machines. It is understood that maximizing production requires optimizing the combination of machine, saw, and liner material, but optimizing these variables on the production machinery is extremely cumbersome and expensive. A reference model is designed to, as accurately as possible, to optimize industrial cutting conditions.

\section{G. Manufacturing Production Model (III)}

A shop floor production model will be developed to maximize the output of the manufacturing processes and help solve layout design optimization problems in the development of new manufacturing capacity. The focus will be on the optimization of new facilities via smart manufacturing, such as automated and optimized material handling, feature-based manufacturing planning and scheduling, as well as robotic application on shop floor. In order to increase underground product life, metallic coating methods to protect tooling surfaces are to be investigated.

\section{PHENORMENON SCIENTIFIC RESEARCH}

Improving oil recovery rate and steam to oil ratio has been a focus of the majority of industrial and research effort in the enhanced oil recovery (EOR) industry. There have been many modifications, refinements, and variations to the SAGD process that have been employed in an effort to increase the method's effectiveness. One of the current areas of interests for researchers and industrial companies is the ability to accurately predict flow performance of fluids.

More specific scientific issues and problems are described hereafter and they are organized according to the three aspects proposed. Within major domains of SAGD operations, fluid mechanics and downhole tooling durability, research challenges are identified for improvement. To the best of the author's knowledge, these domains have not been well studied in the academe or fully understood to a satisfactory level in the industry, allowing the following proposed research topics to remain relevant.

\section{A. Sand Control}

The third research challenge, falling under second major domain of SAGD product development, is to develop an understanding of how to improve the durability of downhole tools while maintaining their performance. Sand control is vital to reliable production in heavy oil recovery processes because sand production is a major obstacle in heavy oil recovery [25], [26]. For example, when SAGD wells are completed with slotted liners in the horizontal section as sand control devices [25], the issues created by sands include slot plugging, erosion of equipment, reduced production rates, and increased cost due to sand disposal and removal [12], [25]. Slot plugging occurs when sand particles bridge in the slot of the slotted liner. This causes the slot to behave as an extension of the reservoir material, increasing the pressure loss as the flow through the slot behaves as Darcy flow rather than open-channel flow [12]. Sand production in the downhole system is abrasive and can erode artificial lift equipment as well as surface equipment, and break into the producer to reduce production rate [16]. If excessive sand production occurs in the producer, the well required to be shut down for a period of time in order to remove the sand, which reduces production rate and increases cost [15]. The investigation of sand control method is necessary both in flow control and downhole tool usage. It is essential to make sure that tools are designed to be durable against sands erosion, and to explore alternative means for sand control to enhance production rate, reduce cost, and decrease pressure loss.

Theoretical and experimental research in sand control aspect consists of two tasks. The first task involves the development and verification of an integrated wellflow-reservoir model linked to a geomechanical reservoir model. The second component includes the design, construction, and troubleshooting of a laboratory facility followed by a testing program to improve slotted liner design criteria and perform a comparative study of the performance of various types of wellbore screen designs.

\section{B. Steam Distribution and Fluide Flowmodeling and Testing in the Undergraound Production System}

The first challenge, falling under the fluid mechanics domain of SAGD operation, is fluid flow modeling and control simulation of both inflow and outflow processes. Inflow is the process when fluids such as steam, water and chemicals, travel from the surface sources into reservoir via the SAGD tubing. Inflow parameters, including the distribution of pressure and temperature, play a significant role in steam chamber efficiency from heel to toe because of their influences on the pressure and heat transfer losses along the horizontal section of the well [10]. Balancing the inflow along the length of a completion will improve performance and efficiency of that well, helping to reduce heel-toe effects, breakthrough of water/gas, and permeability differences [10]. Inflow performance is typically considered to be limited by the open area exposed to the reservoir [11]. It is important to control the inflow of fluid thereby allowing for a more uniform fluid distribution along the horizontal section of the well. Inflow analysis can also be applied to optimize the slot density distribution of the sand control liner to promote more uniform production through the well: inflow resistance has a close relationship with the slot density [12]. Outflow is the process of extracting a mixture consisting of fluid and heavy oil from the SAGD reservoir. The major design goal in outflow performance is to reduce (and in some cases control) the pressure drop across the tool interface.

It is well understood that one of steam's tendencies is to flow to areas of higher permeability. By simulating the fluid 
flow underground with reference to geological data, we can assess the tendencies of steam and predict how it will behave underground. Multiphase flow is a type of flow that often results in liquid carry over in the gas phase and gas entrainment (including natural gas and steam) in the liquid phase [13], [14].

Two flow models are used to analyze flow properties (flow patterns, classifications, transition characteristics, etc) and behaviors such as emulsion [24], [31]. One is the Darcy flow model that covers the flow from the reservoir to the wellbore, and the other is a pipe flow model along the wellbore [24]. The latter accommodates laminar and turbulent two-phase flow [24]. Emulsion is a colloidal system of immiscible fluids in which one is the dispersed phase and the other is the continuous phase. In SAGD systems, the two phases of emulsion is oil and water [31]. REG uses simulators based on the Navier Stokes equations to perform flow simulation, but have not yet arrived at a satisfactory model.

Computational models are used to find the vapor liquid equilibrium and the equations of states of the given fluid [32]. The black oil model is best suited for non-volatile oils and assumes that the two components (oil and gas) are distributed in two hydrocarbon phases (liquid and vapor) [32]. The mechanistic model is a method of describing complex flow phenomena that combines macroscopic conservation principles with empirical closure relationships [33]. There are two types of mechanistic models which are well established. The first is the comprehensive model which separates the flow pattern and pressure gradient to get a prediction of the fluid movement in the well [34]. The second is a unified model which combines flow pattern and pressure gradient to determine a prediction of fluid flow in a well [35].

Although these models and equations are very well established, there are difficulties associated with them. They do not accurately predict inflow performance: The flow of the fluid as it travels along the horizontal part of the SAGD well is well establish but it has been found that the a lot of the losses in energy has been associated with steam getting injected into the production well, which many models fail to predict. There are no well-defined models that can accurately integrate heat transfer and fluid flow properties in a comprehensive fluid simulation. This is especially important for SAGD well pairs because both of those areas are keys for the normal day-to-day operations of the steam. Steam breakthrough has been identified as a major problem in some SAGD installations that greatly reduces efficiency and increases the steam to oil ratio, and this must be addressed.

The scientific phenomena at the root of the techniques used in enhanced oil recovery will be investigated using theory, simulations, and laboratory testing. The results of the phenomenon testing will help us to understand the current state technological situation, and verify the shortcomings of the current techniques: the limitations identified by industry are largely hypothetical, and must be observed and verified to understand the root causes of low recovery metrics. For example, fluid flow is a strong function of the geometry of the flow region and the properties of the fluid. An understanding of both is needed to clearly define the areas requiring research and the approaches that can be used. This phenomenal research aspect will develop understanding, quantitative information and validation data related to the flow in sand screen shell that will impact directly on the design of screen geometry and allow modelling tools to be developed to optimize designs. To verify the theoretical models, specialized multi-scale flow field testing facilities are to be designed and utilized for systematic data collection and analyses.

The second research challenge, also falling under the fluid mechanics domain, is to control (and eliminate) steam breakthrough. Steam breakthrough is said to occur when the steam finds a path of least resistance directly from the injector to the producer [36]. After steam breakthrough occurs, a fraction of the injected steam ends up in the reservoir, causing the steam cycling underground to be reduced substantially [37]. This increases the cost and environmental impact of creating steam and pumping it into the production well [36]. Meanwhile, steam carries with it sands and other fine particles at high speeds as it travels through the production string. This damages the completion string and erodes the slotted liner and casing [7], [38]. Eventually, it will reduce production rates, damage artificial lift equipment, and jeopardize equipment downstream of the well [36]. Another issue caused by steam breakthrough is the higher vapor traffic both at the surface and in the vertical section of the producer, because it will affect the flow of mobile fluids between the wells and reduce the lifting capability of the well [7], [39]. Steam breakthrough causes a decrease in efficiency for several reasons including circulation loss, the existence of tiny fractures, the high viscosity of crude oil, the out-sync of injection and production between the well pairs, the changing tectonic stress field, and the existence of highly permeable paths within the formation [40], [41]. Steam breakthrough can be prevented by way of sub-cool control (also known as steam trap production control) [7], [42]. Subcool is the difference in temperature between the injected steam, at saturated condition, and the actual temperature of the produced fluid [42]. From a thermal efficiency point of view, a high sub-cool value is desirable because it decreases steam injection rates. However, it also results in a reduced production rate due to a higher viscosity and lower mobility of bitumen [31], [42]. Controlling sub-cool within a target value can enhance the infectivity of the formation and serve as a method to enlarge steam chamber. Currently, the investigation of an effective flow control mechanism to prevent steam breakthrough during SAGD operations remains a challenge for the industry.

At this scale level, simulation tools will be developed to model inflow, outflow, and multiphase flow performance in the context of downhole tool applications. Sand control interfaces, sub-cool control and erosion prevention will be considered in these simulations, which will be conducted through numerical modeling and algorithmic development, and validated by the results of the scientific phenomena testing.

Considering the results of the testing and simulations, the team will design enhancements in flow control technology in order to improve recovery rates and Steam to Oil Ratios (SOR), and achieve more effective steam distribution in heavy oil formations. Ultimately, the goal of this project is to develop a new generation downhole tools: multi-scale tests and simulations will verify the quality of the design efforts in 
future projects. Full scale industrial validation will be conducted by oil field operators to prove the effectiveness of new designs.

\section{Scale and Corrosion Prevention}

'Scale is an assemblage of deposits that cake perforations, casing, production tubing, valves, pumps and downhole completion equipment, thereby clogging the wellbore and preventing fluid flow' [43]. Scale buildup, or scale deposition, in oil field is a long term challenge as well as a traditional problem due to the increasingly complicated exploitation environments and their changes. Also, it is the most common and troublesome damage problem in the oilfield [44]. Typically, scales are formed either by direct precipitation from the water that occurs naturally in reservoir rocks or the produced water. The latter happens when the mineral content of the produced water exceeds its saturation point in response to change in conditions including a mixing of different waters, changes in temperature and pressure, water evaporation, or water chemistry and PH changes [28]. In SAGD operations, scale deposits can occur in both production and injection wells. Scale buildup causes various issues. First, scale deposition always results in formation damage, wellbore plugging and corrosion. This eventually decreases oil exploitation efficiency and increases expensive investment [29]. Second, the cost of scale buildup can be high, both in terms of deferred production and necessary remedial treatments. Third, scale growth may prevent fluid inflow, and as consequence oil production falls [29], [30].

The creation of scale is commonly understood in two forms, calcium carbonate and silica, from two different sources. Calcium carbonate scale originates from "various fluids as they mix in the reservoir and/ wellbores under drastically varying sets of thermodynamic, kinetic and hydrodynamic conditions". Silica is created from the impurities in the steam as it is injected and withdrawn during the SAGD process.

Understanding mechanisms of plugging/fouling and failure mechanism of the liners is of both fundamental and practical importance to the development of novel liner design/materials and SAGD technology [9], [18]. It is important to characterize the changes of surface properties of the liners before and after failure as well as to understand the interaction mechanisms between sands, clays, bitumen, asphaltenes, emulsions and liners, which can provide insights into the fouling mechanism and failure mechanism of the liners [9], [45], [46]; and among inorganic minerals (such as calcium carbonate, calcium sulfates) and organics such as asphaltenes in the complex fluid media.

In this part of the research program, the characterizations of the physical/chemical surface properties (e.g. surface energy, hydrophobicity) of liner materials, and experimental measurements on rheological properties and interactions among sand/clay, water, bitumen and liners will be systematically investigated. This effort could provide comprehensive solutions for a better material selection and liner design with improved performances in the SAGD operations for the oil sands industry. The more specific objectives of the proposed research include: (1) Characterize and understand the changes of surface properties of the slotted liners before and after scale failures and explore the failure mechanisms of liner; (2) Elucidate the interaction mechanisms among sand/clay particles, bitumen/emulsion drops and liner before and after failure in various environmental conditions (e.g., ion type, ion concentration, $\mathrm{pH}$, temperature), which can provide valuable information to understand the mechanisms of fouling and plugging; (3) Characterize the rheology of mixture of sands, clays, bitumen and emulsion to better under the flow properties and provide correct input for some of the parameters in the theoretical modelling; (4) Characterize the "scale" or deposit materials from real SAGD operation to better understand the compositions of the deposits and elucidate the scale buildup mechanisms.

In the complex multi-phase system including steam, water, bitumen, sand and solid fine clays, key components in the SAGD tooling system, such as sand control liners, face many detrimental issues such as electrochemical corrosion, plugging and fouling due to deposition of sand/clay and sedimentation of asphaltenes and so on [9], [17], [18]-[22]. All these would lead to failure of the liners and causes serious negative impact on production, which includes, but are not limited to, reduced bitumen production, poor sand control performances and lower quality of bitumen product (with considerable amounts of fine solids that further leads to difficulties in oil/solid/water separation and water treatment and recycling in SAGD operations). Coatings are widely used for corrosion protection [23], however, there are no reports on $\mathrm{H}_{2} \mathrm{~S}$ resistant coating in open literature. The criteria for a good scale buildup management mechanism are: (1) energy efficient; (2) environmentally friendly; (3) technically feasible; and (4) cost effective.

Corrosion related damage significantly shortens the lifetime of the slotted liner of SAGD system, increases the production cost and decreases the overall production efficiency [47], [48].The failed slotted liner clearly shows that both the outer and inner walls of slotted liner suffer corrosion damage (Fig. 9). The major corrosion forms of the slotted liner of SAGD system include sweet corrosion $\left(\mathrm{CO}_{2}\right.$ corrosion) [47], [49], [50], sour corrosion (H2S corrosion), $\mathrm{CO}_{2 /} \mathrm{H}_{2} \mathrm{~S}$ synergistic corrosion, sulfide stress corrosion (SSC) and erosion corrosion. Significant amount of iron sulfide [51], [52], heavy buildup of other corrosion products, clay fines and sands have been observed in the plugged slots, choking them gradually [53]. Hydrogen significantly reduces the corrosion resistan 'ce of carbon steel [50], [54], [55] and weakens the structure's mechanical strength [56] that is important to withstand thermal strains and strain localization [14], [57]. The synergistic effect between the electrochemical corrosion and plastic deformation causes damage of the structural materials much faster than each factor acts alone [58]-[60].

A corrosion cell can be used to determine general corrosion and localized corrosion. Gas mass-flow controllers and a mixer will be used to control the flow rates of $\mathrm{CO}_{2}$ and $\mathrm{H}_{2} \mathrm{~S}$ to the test cell. The proof ring will be used to determine the susceptibility of candidate materials to sulfide stress cracking (SSC). For example, smooth round bar tensile specimens will be machined tested under the action of the applied stress with the specific test solution of $\mathrm{NaCl}$, glacial acetic acid $\left(\mathrm{CH}_{3} \mathrm{COOH}\right)$ and $\mathrm{H}_{2} \mathrm{~S}$ dissolved in distilled water. Elapsed time monitors will record 'time to failure'. 
Erosion corrosion test will be performed in an impingement apparatus to simulate the velocity of the slurry can be varied from $2 \mathrm{~m} / \mathrm{s}$ to $10 \mathrm{~m} / \mathrm{s}$ as well as the sand loading in the solution varied up to $20 \%$ wt with varied angle of impingement, e.g. from $15^{\circ}$ to $90^{\circ}$. A scanning electrochemical workstation will be used for measuring in situ corrosion events on the specimen surface without and with coating. Concurrent images of topographies and potential mappings versus time will be measured to monitor initiation and propagation of localized corrosion events on the specimen surface.

Coatings are widely used for corrosion protection [23]. However, there are no reports on $\mathrm{H}_{2} \mathrm{~S}$ resistant coating in open literature. Hence, it is imperative to explore SAGD coating solutions, surface properties and surface interactions of desired coating materials for liners with better resistance to fouling and corrosion, better sand control and performances in SAGD operations. Further, research effort is necessary to provide evaluation methods in optimizing manufacturing processes and products developed through joint efforts with the industry.

\section{SAGD CFD Analysis for FCDs within the Tools}

The use of Computational Fluid Dynamics (CFD) in the prediction of flows during in situ oil extraction has increased in recent times. Most attention has been given to the overall modelling, using numerical tools such as CMG's STARS ${ }^{\mathrm{TM}}$ [61], [62]. These large scale models that focus on the reservoir are incapable of simulating the detailed flow inside the wells to levels of detail required for the optimization of flow control devices. For example, Kyanpour and Chen [11] used STARS ${ }^{\mathrm{TM}}$ to study the implementation and operation of flow control devices along the complete well with computational cells $35 \mathrm{~m}$ long and $1 \mathrm{~m}$ wide. Other studies that focus on the well bore [7], using for example QFlow ${ }^{\mathrm{TM}}$ from Fractical Solutions, are also very coarse and not adequate to study the detailed flow through the control devices or behavior near the wellbore. Although the flow of steam in the injection well is sufficiently challenging, the simulation becomes increasingly more complex when outflow control devices (OCDs) and detailed injection slot geometries need to be considered. A much more detailed and physically accurate model, as is proposed in this sub- project, is necessary in order to investigate the effect of design and manufacturing changes.

The more complex flow in the production well, consisting of a mixture of oil and water with possible contamination by sand and gas or steam, has been intensely studied in the past, but severe limitations had to be considered in previous models, limiting their accuracy accordingly [63]. The integrated representation of the production well flows that incorporates reservoir effects generally omits the detailed flow through the slots, the lining, and the inflow control devices (ICD). The approach of design optimization and oil production process solution optimization need detailed and accurate quantitative data on the effect of modifications within the parameter space in order to determine directions of improvement and to establish the optimal design and process point.

The proposed research program requires highly accurate simulation results [64] with thorough understanding of traditional flow measurement techniques [65] similar to those used for ultrasound and microwaves applications in the enhanced separation of bitumen from oil sands [66], [67]. The quantitative assessment of modelling accuracy is especially relevant. The main objective of this CFD modelling aspect is the development of CFD models that can accurately predict the behaviour of the injected fluid in the inflow region and of the production oil in the outflow region that are validated against experimental results. The validated models will then be utilized to provide the necessary data for the design and process optimization of flow control devices and slotted liners.

The powerful simulation tools that will be employed in the present project will enable the combined analysis of hydrodynamic and electromagnetic effects on the flow and on the transport and deposition of sand and other contaminants. Once the causes of performance limitations or deterioration are identified, numerical modelling has the potential of accelerating the parametric search for an optimized solution. An accurate simulation can reveal small trends in the response to design changes, which in turn will be used by the optimization algorithm to indicate the best combination of parameters.

This part of the program will apply a modular approach to the development of the capability to simulate the complete inflow and outflow regions, including all aspects of the downhole, injection well and production well, including OCDs and ICDs, but without including the overall reservoir simulation. Each aspect of the physical model will be investigated separately to determine the most suitable model to represent the flow case and to establish optimal simulation parameters, such as boundary conditions, discretization schemes, and convergence strategies. This modular approach will inform the selection of the numerical models to be used in the complete simulation. The modules or research areas will be started in a staggered manner by the individual graduate students involved in the project.

Several leading commercial CFD software packages will be used in this project. For the single phase and multiphase flows, ANSYS CFX will be employed which supports the International Association for the Properties of Water and Steam (IAPWS) tables as built-in fluid properties, which will increase the accuracy of the steam flow simulations. CFX also supports all advanced turbulence and multiphase models that are required for various aspects of the project. For the simulation of the complex non-Newtonian behaviour of the production bitumen ANSYS software Polyflow will be employed. It is uniquely suited for the simulation of complex fluids with temperature and shear dependent viscosity. For the detailed simulation of the deposition of particles due to electromagnetic interaction between the ionic solutions and the wall, a third software package, ANSYS Maxwell, will be used to estimate the electromagnetic field and the forces acting on the particles. The coupling of the electromagnetic and multiphase simulations will be performed through the ANSYS Multiphysics framework.

\section{ENGINEERING DESIGN AND PRODUCt DEVELOPMENT}

Technologically, three aspects are essential for the success use of SAGD technology: sand control, flow distribution control, and instrumentation monitoring. Sand Control is crucial to the effective distribution of steam and separation of 
bitumen from the sand and clay in the reservoir. Around 90\% of heavy oil extraction relies on screen liners for sand control during SAGD operations. Although there is no best method currently employed, there is room to improve the current sand screen application efficiency. As sand seeps through the screen liner, it causes erosion and damages the liner. Emerging sand control methods include slotted liners, wire-wrapping and other types of liner.

A major area of interest for industrial companies and researchers is a method to control the steam underground. Flow control devices (FCD) are used to provide zonal isolation of steam into targeted formations within a reservoir by providing the ability to selectively open or close steam ports in the injection and production zones [68], [69]. FCDs are used to provide zonal isolation of flow in and out of targeted formations within a reservoir by providing the ability to selectively open or close steam ports in the injection and production zones [70], [71]. In conjunction with sand screen liners, they provide sand control, steaming control, and production vacuuming coherently for the SAGD wells [24], [35]. The design of FCDs is focused on improving the performance of the tool in controlling the steam distribution in the reservoir, minimizing pressure drop across the tools, and improving the reliability of the devices over their lifespan. Here the author would like to suggest that smart tooling with adaptive FCDs are to be expected soon with the trend of multi-disciplinary knowledge fusion even though the SAGD operating condition is challenging to many "agile but expensive" technologies.

The main objective of this research aspect is to conceptualize, design, verify and implement new initiatives for FCDs, which represent the new trend of efficiency demand and a growing market area to the industry. FCD models that can accurately predict the behavior of fluid in the inflow region, and of the production oil in the outflow region, will be used to achieve this. In particular, the simulations will model how the FCDs interact with the slotted liner in the injector and production wells, as well as the immediate vicinity of the wells, and the inter-well space. The validated models will provide data for tooling design and process optimization.

By simulating the fluid flow underground with reference to geological data, we can assess the tendencies of steam and predict how it will behave underground. These empirical methods risk causing systematic errors in both liquid and gas metering, and may introduce error into flow data. Inaccurate data from the metering compromises hinders the useful design of flow control tools. It is necessary to understand flow properties in order to create an accurate numerical simulation. Therefore, this part of the design effort will be interfaced hand-in-hand with CFD part where computational models are used to find the vapor liquid equilibrium and the equations of states of the given fluid [71] as represented in the so called black oil model. The black model is best suited for non-volatile oils and assumes that the two components (oil and gas) are distributed in two hydrocarbon phases (liquid and vapor) [71]. The mechanistic model is a method of describing complex flow phenomena that combines macroscopic conservation principles with empirical closure relationships [36]. There are two types of mechanistic models which are well established. The first is the comprehensive model which separates the flow pattern and pressure gradient to get a prediction of the fluid movement in the well [34]. The second is a unified model which combines flow pattern and pressure gradient to determine a prediction of fluid flow in a well [7]. Multiphase flow is a type of flow that often results in liquid carry over in the gas phase and gas entrainment (including natural gas and steam) in the liquid phase [32], [35]. Currently, the method of determining the behavior of multiphase flow is by experimental means, therefore this program also pay great emphasis on experimental aspects of the SAGD flow controls.

Typically, the suggested approach starts with that the current FCD tools are first modeled and fully studied to establish the design specifications and to verify the application requirements considered. New improvement opportunities are to be solicited and evaluated where the new product application specifications will be developed. With the support of new findings from the scientific aspects of this program, FCD performance effectiveness will be simulated and improvements will be introduced iteratively. Eventually, with satisfactory evaluation results via multi-phase flow simulation, new generation FCD system will be justified with the cross-checking of scientific proof findings based on mathematical modeling, computer simulations (e.g. CFD), and virtual performance optimization algorithms; concurrently, preliminary experiments are expected. Finally, "Design for X" aspects will then be optimized, such as design for manufacturing, cost, and modularization. Finally, the product design will go through optimization and prototype tests.

This part of the research will also develop an advanced knowledge-based product development methodology and system to support the quick and intelligent generation of an initial solution for a given in-situ project. The research effort will be based on advanced feature technology and will embed SAGD technology "know-how" into the design models of a set of FCD tools. Therefore, other than typical design documents, such as product drawings, specification documents, operation manuals and performance guides, the design research effort will also include advanced feature modeling for computer-aided design and performance evaluation, prototyping, and preliminary testing. Advanced functional, behavioral and multi-physics features will be investigated, enabling the study of complex chemical/mechanical/physics inter-disciplinary relations.

The deliverables expected from this research aspect will be three groups. The first group is related to SAGD tool steaming and sand control design improvement and new generation tooling design based on new findings from the phenomenon simulation findings. Cyclic enhancement design methodology is to be adopted. Special considerations include steaming efficiency, manufacturability, costs and modularity. The typical deliverables include product specifications; conceptual/detailed design CAD models; calculations in mathematical models; conceptual engineering drawings; and patent applications. The second group of deliverables is the design of mechanisms to reduce, to clean-up and further to prevent scale buildup either by using chemical inhibitors/dissolvers/solvent or by using mechanical methods. A new solution is also to be recommended with the fluid innovation chemically that it can reduce scaling and improve recovery rates/efficiencies and partially or fully replace steam. The third group of 
deliverables will be a scientifically validated performance coating that will prevent the buildup of scale and ensure slotted liner performance for the lifetime of the well. This coating will require coating equipment to be designed and implemented into REG manufacturing process.

Eventually, the new application opportunities for industrial products are to be investigated which will create the new business opportunity for the industry with the technological improvement and hence leading to higher oil recovery efficiency and lower costs.

\section{MANUFACTURING INNOVATION AND OPTIMIZATION}

The manufacture of downhole tools is time consuming and expensive. Use slotted liner as an example, eight unique manufacturing processes (plus associated support processes) are deployed: (1) Pre-slot cleaning, (2) Slotting, (3) Washing, (4) De-burring, (5) Slot Profiling (Seaming), (6) Coating, (7) Pipe Conveyance, and (8) Inspection. The productivity and quality of the manufacturing processes have a large effect on the performance. Studying machine capability thoroughly allows the maximum rate to complete a manufacturing process as designed at full-scale operation. A capability study is planned identifying machine-specific optimization space on the production process, minimizing the influence of external variables wherever possible [72]. Further research includes product and material tracking, emerging technology research for process improvement, and the management of machine operating data. For some processes, automated custom machines were developed to perform special manufacturing functions; they are constrained by the manufacturing methods, reliability, and production efficiency. Often than not, such customized machines (like slotting machines) are not completely modeled for their cutting strength, nor are the cutting tools analyzed. Some machines perform beyond their designed capabilities, while others struggle to meet the design acceptance criteria. To date, research efforts have been made to assess and enhance each machine's capability using techniques such as feature engineering and knowledge based approach [69], [73]-[75] but none of these techniques have wide adaptability in typical SAGD tooling production. When the manufacturing process is complicated, more than one algorithm is required obtain the required accuracy.

Further, with the new products such as ICDs and OCDs, the research program is to develop and optimize the new capacity. Enhancement can also be done by increasing design manufacturing integration (DMI) [76]. Other process improvements can include: simplifying procedures by combining several procedures; developing automated solutions for manual tasks; exploring non-traditional methods, like additive manufacturing, laser cutting and welding, electrical discharging cutting. Some companies have been developing coated products, so the relevant manufacturing methods, equipment development, process optimization and quality assurance become imperative; and hence research is urgently required in chemical and material engineering.

\section{ENGINEERING INFORMATICS MODELING FOR MULTI-DISCIPLINARY SYSTEM DEVELOPMENT}

This part is to develop an advanced knowledge-based
SAGD development software toolkit to support quick and intelligent generation of an initial solution for a given in-situ project. Some multi-disciplinary informatics technologies, such as advanced feature technology [77], can be used to embed SAGD technology "know-how". A comprehensive semantic and heuristic product model for sand and flow control functions will be created with associated tooling design knowledge, engineering constraints and built-in intellectual property based on industry's existing product specifications, and customer requirements. A mathematical model will be embedded as constraints for tooling design. The relations between reservoir characterizations and the optimized sand and flow control strategies will be encapsulated within application templates for customer specific application customization. Next, the software modules can utilize the engineering design and manufacturing knowledge accumulated from this joint research program. Then this research effort will develop an effective and generic software "engine" or a platform to provide the necessary engineering constraint checking, to support design innovation initiation, and to manage routine design automation so that custom solutions can be developed effectively and timely. This research also aims to reduce the dependency on specialist expertise.

To elaborate, first a coherent information system modeling for SAGD tooling design and related physics phenomena is to be carried out. The product lifecycle domain semantics modeling related to the industrial technologies will then be followed. Features within the typical commercial products are to be identified, modeled and structurally defined in feature templates for software solution development use. A generic constraint management and solving engine is to be developed next. Then the development of a prototype SAGD production management software toolkit is to be completed. Initially the software prototype can be a specific product development advisory tool and tested as a functional module for customized oil patch solution development. Once that functionality is achieved, the phenomenon model representation and integration mechanisms and some pilot design aspects or effect models are to be generically implemented. Then the conceptual function of design validation by applying generic constraint solving methods is to be developed. With some further optimization algorithms towards productivity are to be focused, a sustainable knowledge-based custom solution design system for SAGD technology management can be achieved and ready for future commercialization and further development. Eventually, as an essential performance benchmark system, well production string models will be established and their performance simulated. The design of the well strings with the sand screen liner as the interfacial system with the oil sands formation will be represented, implemented and interfaced with CFD models for effective simulations. Failure modes will be identified and their effects evaluated.

\section{SUMMARY AND CONCLUSIONS}

This paper describes a research proposal for a comprehensive and multi-disciplinary technology SAGD solution. Four key research aspects are studied: (1) Phenomenon modeling and analysis in the oil reservoir 
production using SAGD tools; (2) Applied technologies embedded into key SAGD products, such as sand screen liners and flow control devices; (3) Manufacturing process enhancement in order to address productivity and cost issues in the related industry; (4) Knowledge engineering solution development. A specific software tool will be able to support incremental knowledge engineering of industrial companies with modular implementation of different SAGD technologies. A direct measure of the success of this proposed research program will be the measured improvements in the oil recovery ratio in SAGD which is currently the hurdle for the heavy oil industry, economically and ecologically. In conclusion, this proposed program aims at developing a sustainable, new-generation SAGD technology enabled by new scientific discoveries and advanced downhole tools. The new knowledge, product technologies, and engineering informatics scheme to be generated will be very useful for all unconventional oil production companies all over the world.

\section{REFERENCES}

$\begin{array}{llll}\text { Energy } & \text { Alberta. } & \text { [Online]. } & \text { Available: } \\ \text { http://www.energy.alberta.ca/ourbusiness/oilsands.asp } & \end{array}$ [2] Center for Energy ${ }^{\mathrm{TM}}$. [Online]. Available: http://www.centreforenergy.com/AboutEnergy/ONG/OilsandsHeavy Oil/Overview.asp?page $=5$

[3] C. V. Deutsch and J. A. McLennan. Guide to SAGD (steam assisted gravity drainage) reservoir characterization using geostatistics. [Online]. Available: http://www.centreforenergy.com/AboutEnergy/ONG/OilsandsHeavy Oil/Overview .asp?page=5http://web.archive.org/web/2008120903073 3/http://www.uofaweb.ualberta.ca/ccg/pdfs/Vol3-IntroSAGD.pdf

[4] MEG Energy, Steam-Assisted Gravity Drainage (SAGD). [Online]. Available:

http://www.megenergy.com/operations/steam-assisted-gravity-draina ge-sagd

[5] Halliburton, Sand control. [Online]. Available: http://www.halliburton.com/en-US/ps/stimulation/sand-control/defaul t.page

[6] J. Xie et al., Slotted Liner Design for SAGD Wells, WorldOil, June 2007, pp. 67-75.

[7] S. Das, "Improving the performance of SAGD," in Proc. SPE/PS-CIM/CHOA International Thermal Operations and Heavy Oil Symposium, 2005, pp. B371-B378.

[8] C. J. Coberly, "Selection of screen openings for unconsolidated sands," Drilling and Production Practice, pp. 37-189, 1938.

[9] D. B. Bennion, S. Gupta, S. Gittins, and D. Hollies, "Protocols for slotted liner design for optimum SAGD operation," in Proc. Canadian International Petroleum Conference, Calgary, Alberta, Canada, 2009.

[10] Halliburton. EquiFlow ${ }^{\circledR}$ inflow control devices. [Online]. Available: http://www.halliburton.com/public/cps/contents/Data_Sheets/web/H/ H05600.pdf

[11] Z. Chen et al., "A new approach for designing steam splitters and inflow control devices in steam assisted gravity drainage," in Proc SPE-165487-MS, SPE Heavy Oil Conference-Canada, 11-13 June, Calgary, Alberta, Canada, 2013.

[12] CMG. (2013). Training Catalogue. [Online]. Available: www.cmgl.ca

[13] V. Oballa, D. A. Coombe, and L. Buchanan. "Aspects of discretized wellbore modelling coupled to compositional/thermal simulation,' Journal of Canadian Petroleum Technology, vol. 36, no. 4, pp. 45-51, 1997.

[14] T. W. Stone, N. R. Edmunds, and B. J. Kristoff, "Comprehensive wellbore/reservoir simulator," in Proc. SPE 18419, $10^{\text {th }}$ SPE Symposium on Reservoir Simulation, Houston, February, 1989.

[15] A. Siu, Y. K. Li, L. Nghiem, and R. A. Redford, "Numerical modeling of a thermal horizontal well," in Proc. CIM/SPE International Technical Meeting, Calgary, June 1990.

[16] D. Collins, L. Nghiem, R. Sharma, Y. Li, and K. Jha, "Field scale simulation of horizontal wells," JCPT, vol. 31, no. 1, pp. 14-21, 1992.

[17] J. L. Stalder, "Test of SAGD flow-distribution-control liner system in the Surmont Field, Alberta, Canada," SPE Journal of Canadian Petroleum Technology, vol. 52, no. 2, pp. 95-100, 2013.
[18] D. Dall'Acqua, G. L. Turconi, I. Monterrubio, and M. D. Allen, "Development of an optimized tubular material for thermal slotted liner completions," J Can Petrol Technol., vol. 49, pp. 15-22, 2010.

[19] N. R. Edmunds and S. D. Gittins, "Effective application of steam assisted gravity drainage of bitumen to long horizontal well pairs," $J$ Can Petrol Technol., vol. 32, pp. 49-55, 1993.

[20] P. A. V. Valk and P. Yang, "Investigation of key parameters in SAGD wellbore design and operation," J Can Petrol Technol., vol. 46, pp. 49-56, 2007.

[21] J. Y. Yuan and R. McFarlane, "Evaluation of steam circulation strategies for SAGD startup," J Can Petrol Technol., vol. 50, pp. 20-32, 2011.

[22] C. Zimmer, D. Richter, J. Person, J. Tilley, and M. Bittar, "Drilling a better pair: New technologies in SAGD directional drilling," J Can Petrol Technol., vol. 51, pp. 115-126, 2012.

[23] H. Zhang, J. Zou, N. Lin, and B. Tang, "Review on electroless plating $\mathrm{Ni}-\mathrm{P}$ coatings for improving surface performance of steel," Surface Review and Letters, vol. 21, no. 4, pp. 1430002-1-13, 2014.

[24] T. M. V. Kaiser, S. Wilson, and L. A. Venning, "Inflow analysis and optimization of slotted liners," SPE Drilling and Completion, vol. 17, no. 4, pp. 200-209, 2002

[25] F. Brent, "Sand control in steam assisted gravity (SAGD) Wellbores," MSC thesis, University of Calgary.

[26] Z. Chen, "Reservoir simulation: Mathematical techniques in oil recovery," in Proc. the CBMS-NSF Regional Conference Series in Applied Mathematics, SIAM, Philadelphia, PA, 2007, vol. 77.

[27] Z. Chen, I. Gates, S. Larter, M. Pooladi-Darvish, and R. Wang, Advanced Reservoir Engineering, 2008.

[28] A. H. Shar, T. Ahmad, and U. B. Bregar, "Scale buildup, its detection and removal in high temperature gas wells of Miano field," in Proc. SPE Production and Operations Symposium, 2010, pp. 396-410.

[29] C. Q. Ren, X. Wang, L. Liu, and L. Gao, "Design and evaluation of compound chemical scale remover," Advanced Materials Research, vol. 236-238, p. 1, pp. 664-667, 2011.

[30] A. I. V. Yukos et al., Scaling problems in western Siberia," in SPE 5th International Symposium on Oilfield Scale, UK, 29-30 January, 2003.

[31] C. C. Ezeuko, J. Wang, and I. D. Gates, "Investigation of emulsion flow in SAGD and ES-SAGD," in Proc. SPE Heavy Oil Conference Canada, vol. 2, pp. 929-944, 2012.

[32] P. N. Azom and S. Srinivasan, "Mechanistic modeling of emulsion formation and heat transfer during the steam-assisted gravity drainage (SAGD) process," in Proc. SPE (Society of Petroleum Engineers) Annual Technical Conference and Exhibition, 2009, vol. 6, pp 3788-3801.

[33] Z. Wang, S. Li, and C. Yan, "A study of fluid flow mechanism for cold production with sand and single-well fine numerical simulation in heavy oil reservoirs," in Proc. SPE/PS-CIM/CHOA International Thermal Operations and Heavy Oil Symposium, 2005, pp. 1-6.

[34] Y. Taitel and A. E. Dukler, "A model for predicting flow regime transitions in horizontal and near horizontal gas-liquid flow," AIChE Journal, vol. 22, no. 1, pp. 47-55, Jan. 1976.

[35] I. N. Alves, F. J. S. Alhanati, and O. Shoham, "A unified model for predicting flowing temperature distribution in wellbores and pipelines," SPE Production Engineering, November 1992, pp. 363-367.

[36] M. Bedry and J. Shaw, "Using a new intelligent well technology completions strategy to increase thermal EOR recoveries-SAGD field trial," in Proc. SPE EOR Conference at Oil and Gas West Asia 2012, OGWA - EOR: Building towards Sustainable Growth, 2012, vol. 2, pp. 559-569.

[37] S. Das, "Application of thermal recovery processes in heavy oil carbonate reservoirs," in Proc. the SPE Middle East Oil \& Gas Show and Conference, Kingdom of Bahrain, 11-14 March, 2007.

[38] R. T. Brooks and T. W. Davis, "Optimizing steam injection in heavy oil reservoirs," in Proc. SPE - 14th Abu Dhabi International Petroleum Exhibition and Conference, 2010, vol. 3, pp. 1881-1890.

[39] J.-Y. Yuan and R. McFarlane, "Evaluation of steam circulation strategies for SAGD startup," Journal of Canadian Petroleum Technology, vol. 50, no. 1, pp. 20-32, 2011.

[40] R. T. Brooks and H. Tavakol, "Experiences in eliminating steam breakthrough and providing zonal isolation in SAGD wells," in Proc. SPE Heavy Oil Conference Canada, 2012, vol. 2, pp. 1272-1282.

[41] X. H. Dong and H. Q. Liu, "Investigation of the features about steam breakthrough in heavy oil reservoirs during steam injection," Open Petroleum Engineering Journal, vol. 5, no. 1, pp. 1-6, 2012.

[42] I. Gates and D. R. Gotawala, "SAGD sub-cool control with smart injection wells," in Proc. SPE - 71st European Association of Geoscientists and Engineers Conference and Exhibition, 2009, vol. 3, pp. 1551-1564.

[43] M. Crabtree et al., "Fighting scale - removal and prevention," Oilfield Review, Autumn 1999. 
[44] J. A. Mora, S. G. Pinto, and F. Kondo, "The challenge of producing and stimulating a deep sandstone-carbonate reservoir with combined organic and inorganic formation damage," in Proc. SPE Western Regional Meeting, 2009.

[45] J. N. Israelachvili, Intermolecular and Surface Forces, p. 674, Academic Press, Burlington, MA, 2011.

[46] S. Saraji, L. Goual, and M. Piri, "Adsorption of asphaltenes in porous media under flow conditions," Energy \& Fuels, vol. 24, pp. 6009-6017, 2010.

[47] L. T. Popoola, A. S. Grema, G. K. Latinwo, B. Gutti, and A. S. Balogun, "Corrosion problems during oil and gas production and its mitigation," International Journal of Industrial Chemistry, vol. 4, , p. 352013.

[48] D. Lusk, M. Gupta, K. Boinapally, and Y. Cao, "Armoured against corrosion," Hydrocarbon Engineering, vol. 13, no. 11, pp. 115-118, 2008.

[49] C. de Waard and U. Lotz, "Prediction of $\mathrm{CO}_{2}$ corrosion of carbon steel," EFC Publication, The Institute of Materials, London, no. 13, 1994

[50] K. L. J. Lee and S. Nesic, "EIS investigation of $\mathrm{CO}_{2} / \mathrm{H}_{2} \mathrm{~S}$ corrosion," Corrosion, 2004

[51] F. W. H. Dean and S. W. Powell, "Hydrogen flux and high temperature acid corrosion," Corrosion, 2006.

[52] H. Ma et al., "The influence of hydrogen sulfide on corrosion of iron under different conditions," Corrosion Science, vol. 42, no. 10, pp. 1669-1683, 2000.

[53] U. G. Romanova and T. Ma, "An investigation of the plugging mechanisms in a slotted liner from SAGD operations," GeoConvention, 2013.

[54] Y. M. Zeng, J. L. Luo, and P. R. Norton, "New interpretation of the effect of hydrogen on the ion distributions and structure of passive films on microalloyed steel," Journal of the Electrochemical Society, vol. 151, pp. B291-B298, 2004.

[55] Y. M. Zeng and J. L. Luo, "Electronic band structure of passive film on x70 pipeline steel," Electrochim. Acta, vol. 48, pp. 3551-3562, 2003.

[56] B. T. Lu, J. L. Luo, P. R. Norton, and H. Y. Ma, "Effects of dissolved hydrogen, elastic and plastic deformation on active dissolution of pipeline steel in anaerobic groundwater of near-neutral pH," Acta Materialia, vol. 57, pp. 41-49, 2008.

[57] S. Paitakhati, 2011, "Post SAGD in-situ combustion hybrid recovery method for oilsand reservoirs," PhD dissertation, University of Calgary.

[58] B. T. Lu and J. L. Luo, "Synergism of electrochemical and mechanical factors in erosion-corrosion," Journal of Physical Chemistry B, vol. 110, pp. 4217-4231, 2006.

[59] B. T. Lu, J. F. Lu, and J. L. Luo, "erosion-corrosion of carbon steel in simulated tailing slurries," Corrosion Science, vol. 53, pp. 1000-1008, 2011.

[60] F. Mohammadi and J. L. Luo, "Effects of particle angular velocity and friction force on erosion enhanced corrosion of 304 stainless steel," Corrosion Science, vol. 52, pp. 2994-3001, 2010.

[61] S. Akin and S. Bagci, "A laboratory study of single-well steam-assisted gravity drainage process," J. Petrol. Sci. Eng., vol. 32, pp. 23-33, 2001.

[62] T. Q. C. Dang et al., "Numerical simulation of SAGD recovery process in presence of shale barriers," Thief Zones, and Fracture System, Petroleum Science and Technology, vol. 31, no. 14, pp. 1454-1470, 2013.

[63] O. Cazarez-Candia, O. C. Benítez-Centeno, and G. Espinosa-Paredes, "Two-fluid model for transient analysis of slug flow in oil wells," International Journal of Heat and Fluid Flow, vol. 32, pp. 762-770, 2011.

[64] C. F. Lange, M. Breuer, and F. F. Durst, "Momentum and heat transfer from cylinders in laminar flow at $10^{-4} \leq \mathrm{Re} \leq 200$," Int. J. Heat Mass Transfer, vol. 41, no. 22, pp. 3409-3430, 1998.
[65] J.-M. Shi, D. Gerlach, M. Breuer, F. Durst, and C. F. Lange, “Analysis of heat transfer from a single wire close to a wall," Phys. Fluids, vol. 15, no. 4, pp. 908-921, 2003.

[66] N. Semagina and C. F. Lange, "How to design silent control experiments for ultrasound-assisted oil sands extraction and upgrading: Computational study," J. Petrol. Sci. Eng., 2013.

[67] R. Karamudi, N. Semagina, and C. F. Lange, "Thermal kinetics analysis in microwave-assisted oil sands separation," Fuel Processing Technology, 2014.

[68] Regent, Presentation on ISA 2013. [Online]. Available http://isaedmonton.org/wp-content/uploads/01_RegentSteamSDPPres entation.pdf

[69] Regent Energy Group. [Online]. Available: http://www.regentenergygroup.com/machine-tools/staging-divertor-p up.aspx

[70] L. Perdomo, C. P. Damas, and E. F. Rincon, "The impact of steam placement control on SAGD performance: A numerical study from the orinoco heavy oil belt," in Proc. World Heavy Oil Congress, Edmonton 10-12 March, 2008.

[71] A. J. Mora, S. G. Pinto, and F. Kondo, "The challenge of producing and stimulating a deep sandstone-carbonate reservoir with combined organic and inorganic formation damage," in Proc. SPE Western Regional Meeting, 2009.

[72] D. Thierig, "Machine capability and process capability in analytical chemistry," Stahl und Eisen, vol. 111, no. 10, pp. 83-87, Language: German, 1991.

[73] Regent, Equipment Catalogue. (Sept. 21, 2013). [Online]. Available: http://www.regentenergygroup.com/products.aspx

[74] C. Gologlu, "Machine capability and fixturing constraints-imposed automatic machining set-ups generation," Journal of Materials Processing Technology, vol. 148, no. 1, pp. 83-92, 2004.

[75] M. M. Padgett, L. E. Vaughn, J. A. Lester, "Statistical process control and machine capability in three dimensions," Quality Engineering, vol. 7, no. 4, pp. 779-796, 1995.

[76] C. Song et al., "Assessment of implementation capability for design-manufacturing integration based on support vector machine," Key Engineering Materials, vol. 522, pp. 842-846, 2012.

[77] Y.-S. Ma, Semantic Modeling and Interoperability in Product and Process Engineering, Springer, London, p. 389, 2013.

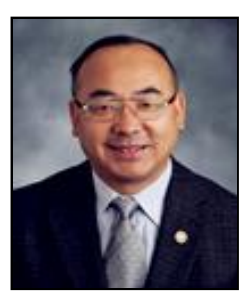

Yongsheng Ma has been a full professor with the University of Alberta since 2013. Dr. Ma has also been a registered professional engineer with APEGA, Canada since 2009. Currently he teaches capstone design projects, engineering informatics and manufacturing processes. His research areas include interdisciplinary heavy oil recovery production tooling engineering, feature-based product and process modeling, plastic molding simulation and mold design optimization, CAD/CAE integration, CADCAM, ERP informatics modeling, and product lifecycle management. Dr. Ma received his B.Eng. degree from Tsinghua University, Beijing in 1986, M.Sc. and Ph.D. degrees from UMIST, UK in 1990 and 1994 respectively. From 2000 to 2007, he had been an Associate Professor with Nanyang Technological University, Singapore; and from 2007 to 2013, University of Alberta. He served as an associate editor of IEEE Transaction of Automation Science and Engineering (2009-13); and since 2012, has been an editor of Advanced Engineering Informatics. Before 2000, Dr. Ma had worked at Ngee Ann Polytechnic in Singapore and then Singapore Institute of Manufacturing Technology (SIMTech). 